\title{
Time for bioethics and business to start talking
}

\section{Commerce and idealism need not be mutually exclusive.}

Sir - The cultural rift between bioethicists and biotechnologists has resulted in a situation where each sees the other as single-minded. It is all too easy for bioethicists to assume that businesses are entirely driven by the profit motive, with science merely a slave to this machine. For their part, many corporations deliberately exclude themselves from debating ethics, claiming that their expertise is grounded in the reality of (say) healthcare needs or food production, and dismissing bioethicists as caught up in moral abstractions.

Both groups need to realize the imperative for interaction, particularly if they are truly dedicated to social responsibility. Perhaps the best way to achieve this is to explain how each field can better serve its respective goals by building a constructive rapport. Regrettably, there are only a few on each side of the fence who have come to this realization. Each group must overcome its misgivings, embrace common goals, and try to appeal to the sensibilities of the other.
Put simply, bioethicists and business people need to realize how valuable they can be to each other while honouring their own professions.

Industry representatives are well aware that to meet their goals of stakeholder satisfaction, sustainability, profit and continuing research, they have to understand the intricacies of the life-science landscape. This requires understanding patient interests, legal and regulatory trends, market segmentation and international receptiveness to products. In the most general sense, bioethics offers a context for technology — socially, economically and politically — which is critical given the complexities of the biotechnological enterprise.

If bioethics offers industry a context, how can industry reciprocate? The answer is that it offers relevance to bioethics. Bioethics, amongst other things, is concerned with the just development and distribution of medical and other lifescience technologies. The discipline has become concerned with setting policies for scientific grant funding, academic research, and private and public hospitals. But when asked to address the bioscience industry, the question becomes eclipsed by debates over the ethical propriety of working with private firms rather than how to engage them. For instance, helping corporations to understand the ethical context of their research is seemingly less important than holding endless discussions over conflicts of interest.

I think it is important for bioethicists to understand the part of the object of its study that is substantially influenced by commercial factors. Failure to engage industry will eventually lead the discipline towards irrelevance, as it constructs artificial boundaries based on fashions that neglect the important and pervasive role of commerce.

Rahul K. Dhanda

Bioethics Program, Interleukin Genetics, 135 Beaver Street, Waltham,

Massachusetts 02452, USA

\section{Tools for modelling biological processes}

Sir — Without minimizing problems presented by large-scale ranges, as indicated in H. Kitano's good overview article in your Computational Systems Biology Insight (Nature 420, 206-210; 2002), I think that the potential leverage offered by a 'layered platform' approach to modelling biological processes deserves some mention.

Members of the Biomedical Information Science and Technology Initiative (BISTI) of the US National Institutes of Health (NIH) concluded in 1999 that if we properly develop software tools, "time spent reinventing the same [software] processes in one laboratory after another will be freed for basic research" (see www.nih.gov/ about/director/060399.htm). The NIH subsequently started a programme focusing on tool development, called Innovations in Biomedical Information Science and Technology, and, more recently, established the National Institute of Biomedical Imaging and Bioengineering.

How exactly does one avoid reinventing the wheel? As an illustration, transport phenomena are involved in biological/ physiological processes whose scale ranges from individual protein production, via tissue nourishment and organ functionality, to whole-organism homeostasis. While transport is the common underlying theme, each system differs in geometry and the properties of materials involved.

A single 'transport platform' that allows a user to configure the geometry with finite element analysis and to specify 'material' behaviour with specific constitutive equations could simulate applications in all biological transport systems. The remaining 'layers' of the total solution fluid mechanics, chemical reactions, heat transfer, matrix inversions and so on would be supplied by experts in these disciplines and managed automatically.

The feasibility of this approach, and its compelling economic logic, is supported by the success of analogous platforms in other venues, for example ANSYS in structural mechanics (see www.ansys. com). What is perhaps not so obvious is that biologists, physiologists, clinicians and others can model phenomena that they understand without being required to make a major time investment in such matters as analytical mechanics, optimum matrix inversion techniques, database management or graphical user interfaces.

As we begin the effort to develop computationally intensive models of biological phenomena, it is worthwhile to pause for a moment and think about the structure of the tools that are needed.

\section{John Keane}

JKA Inc, 273 Jefferson Road, Princeton,

New Jersey 08540, USA

\section{Complexity may teach us a simple lesson}

Sir - In his Concepts essay "Progressive evolution: aspirational thinking" (Nature $240,611 ; 2002)$, Henry Gee failed to mention the most obvious source (perhaps the second most obvious, after our own vanity) of the idea that evolution is progressive. This is that evolution has actually been progressive, insofar as it has produced increasingly complex organisms over time.

It may be that this has occurred by way of undirected processes, but one can hardly blame people, including scientists, for arriving at the conclusion that evolution is progressive, given its history here on Earth. Of course, this requires a value judgement that more complexity is better, but it is not surprising that human beings will think that the complexity of a human is 'better' in some sense than that of a cockroach.

Michael Sierk

Department of Biochemistry and Molecular Genetics, University of Virginia, PO Box 800733, Charlottesville, Virginia 22908-0733, USA

\section{correspondence}

Contributions to Correspondence may be submitted to corres@nature.com. They should be no longer than 500 words, and ideally shorter. Published contributions are edited for length. 